\title{
Technologies Transfer: Domestic and Foreign Experience
}

Doi:10.5901/mjss.2015.v6n3s4p185

\section{Inna Sergeevna Bogomolova}

\author{
Elena Konstantinovna Zadorozhnyaya
}

Alexandr Anatolevich Koretsky

Southern Federal University 05/42 Bolshaya Sadovaya Str., Rostov-on-Don, 344006, Russia

Email: isbogomolova@sfedu.ru, ekzadorozhnyaya@sfedu.ru,koretsky@ttpark.ru

\section{Abstract}

Questions technology transfer and commercialization in the Russian Federation are current and due to the need for sustainable economic development of innovative type. The intended use of foreign experience, technology transfer can be one of the mechanisms for funding of basic and applied research. In this regard, research and adaptation of foreign experience is of paramount importance for the development of technology transfer in Russia. The object of research is the process of organizing the transfer of technologies in Russia and abroad. The article describes the features of stimulating technology transfer in the countries occupying a leading position in the implementation of the innovation potential. The basic principles for improving the effectiveness of technology transfer abroad, which can be adapted and implemented in the Russian practice. Based on the study of foreign experience, formed by the direction of increasing the rate of technology transfer at the international, national, sectoral and inter-organizational level of the national innovation system.

Keywords: technologies transfer, innovation, commercialization, national innovation system, domestic and foreign experience

\section{Introduction}

In modern conditions of globalization the special role in acceleration on economy development is taken by scientific researches, creation and implementation of new technologies. The urgency of technologies transfer in this regard increases as one of the most important stages of innovative process and realization of procedure of new scientific and technical knowledge transfer from their developers for implementation in high technology production.

The technologies transfer assumes not just the knowledge transfer, but also their transformation into innovative technologies with active participation of the developer, manufacturer and final consumer of the product created by means of this innovation. Therefore it is necessary to give the main attention in the course of technologies transfer not just directly on very technologies, but on relations particularities and interactions of innovative process subjects (Sharif and Kabir, 1976).

For development of high technology production it is necessary to form the centers of technologies transfer which key task is the innovative technologies promotion, based on creation of effective interaction of subjects of scientific, manufacturing and investing activities that as a whole will allow raising the competitiveness of the Russian economy.

\section{Characteristic of the Experience of Foreign Countries in the Implementation of Technology Transfer}

In 2014, the Global Innovation Index countries (GII 2014), published by Cornell University, School of Business, INSEAD and the World Intellectual Property Organization, led by Switzerland, the United Kingdom and Sweden, and significantly increased the index of the region's countries in Africa south of the Sahary (Research INSEAD: The Global Innovation Index, 2014). According to the GII 2014, the leader is the fourth consecutive year, Switzerland. United Kingdom rose by one notch, finishing second, and is followed by Sweden. This year, the top ten also entered Luxembourg (9th place) (Table 1).

Table 1. The Global Innovation Index in some countries in 2014

\begin{tabular}{|l|l|}
\hline 1. Switzerland (1 in 2013) & 6. The United States of America (5) \\
\hline 2. The United Kingdom (3) & 7. Singapore (8) \\
\hline 3. Sweden (2) & 8. Denmark (9) \\
\hline 4. Finland (6) & 9. Luxembourg (12) \\
\hline 5. Netherlands (4) & 10. Hong Kong (China) (7) \\
& \\
& 185
\end{tabular}


The study recorded 143 countries around the world that produce the world's GDP, more than $99 \%$. This year, Russia ranked 49th place (in 2012 Russia ranked 52 position).

In this regard, important to consider the experience of technology transfer of advanced countries in terms of innovative features and results - Switzerland, USA, United Kingdom.

Switzerland is concentrating significant efforts to commercialize its scientific and technological capacity. The State Commission for Technology and Innovation serves as the Agency for innovation and development at the state level, supports the scientific and applied research supports the promotion of public investment in innovative financing sektor. However, the financing of innovation is generally done through private investment. In the industrial sector, technology transfer is realized on the basis of technopark structures (llyin, 2013).

Also in Switzerland, the exchange of scientific and technological information between the subjects of innovation activity is realized with the participation of the Swiss Association of Technology Transfer, established in 2003 (Switzerland's information portal).

The examination of foreign experience show that in many countries there are different types of centers of technologies transfer functioning, however their missions and the purposes are practically identical and consist in realization of help in the search, assessment and innovations plantation. The forms of the centers of technologies transfer often depend on the social and economical level of national economy development, in particular, on the possibilities of governmental financing, the legislative base, etc. (Reamer, 2003).

The investigation of foreign experience on organization of the centers of technology transfer is important for Russia from the point of view of forming new and making perfect of the existing technologies transfer centers taking into account an economic situation in the country and innovative potential of economy development.

So in the USA for the purpose of having an effective technologies transfer in 1986 have been created the consortium of federal scientific laboratories that stimulated an establishment of interrelations between the companies and federal and regional scientific divisions. In the USA it is conducted an active information support of subjects' innovative activity: free of charge telephone line with representatives of the databases necessary for technology transfer, publication of catalogs, carrying out the trainings (Bykovsky et al., 2006).

For Russia it would be reasonable to offer a financial support to the existing technologies transfer centers created on a base of higher educational institutions, for the purpose of stimulation an effective search of innovations market. It is connected with that not always the Russian centers of technologies transfer have an access to sales channels; the databases are charging rather high prices for this purpose that complicates a successful technology transfer.

One of the forms of technologies transfer center in Great Britain can be considered the British Technological Group (BTG) which was created in 1981 as the state organization and went private in 1992 according to the special scheme (Arora and Gambardella, 2010).

Thee given organization facilitate the technology transfer from universities and other research establishments of governmental sectors into industry on the basis of licensing. Among its functions there took places an examination and protection of foreign intellectual property in Great Britain. Here it should be noted that the activity of the Russian centers on technology transfer should be directed not just on search of the Russian inventions, but also on innovation of science intensive companies of nonresidents, which are producing the inventions in the Russian market.

This, on the one hand, will promote the forming of trust and support for our state by the world community, and on the other hand it will stimulate an innovative development of Russia.

Now in the USA and Great Britain there indirect methods are used on stimulation of the centers of technology transfer, such as customs and tax remissions.

In Germany the centers of technologies transfer are presented by various joint research associations in the industries which are financed at the expense of subsidies of German government. Their main objective is assistance on implementation into industries of high technologies and carrying out the researches of nation-wide value. For small enterprises needy in technology transfer, the government provides the subsidies in the amount of $40 \%$ from total cost of the research ordered (Ceccagnoli and Hicks, 2009).

The government of France supports an extensive network of the centers specialized on technologies transfer, but yet this network differs from the existing in the Russian Federation.

It is reasonable to strengthen the interaction between the Russian centers of technologies transfer in the course of search for markets, buyers and informing them on certain technologies.

The various centers of technologies transfer depending on features of their creation (based on higher education institutions or industrial corporations) possess the different databases on innovations therefore the well-timed information exchange will promote fast and successful technology transfer.

The experience of Poland is the most informative as it is connected with Russia by general historical roots. In 
Poland the non-commercial centers of technologies transfer are created and developed based on higher education institutions and other research establishments and they are financed by the government (Bonkovsky and Klepka, 2005).

In other European countries, such as Finland, Belgium, Denmark, Portugal it is created the special centers for cooperation of the universities and industry, the interdisciplinary centers, the innovative centers of technology transfer in small and medium business, as a rule, they are operating at the regional level. For Russia the same tendency is characteristic, though in connection with availability of financial restrictions their development derives more slowly.

The experience of the Asian countries (China, South Korea, Thailand, Singapore and Taiwan) is based on that the main lever influencing on technologies transfer centers development presents the preferential taxation. The system of taxation has a flexible nature and depends on strategic scientific and industrial reference points of the state.

The basic principle of the organization Centre for Technology Transfer abroad is that the center has implemented a complete innovation chain, which allows to bring an innovative idea in the creation of a small business.

\section{The Possibility of Using Foreign Experience in the Russian Practice of Technology Transfer}

The transfer of technologies in Russia can be organized with the use of various mechanisms combination approved in the West (Table 2).

Table 2. The particularities of technology transfer stimulation abroad and their possible application in Russia

\begin{tabular}{|c|c|c|}
\hline Country & Directions of technologies transfer stimulation & Possibility of using in Russia \\
\hline USA & $\begin{array}{l}\text { Financing of researches and development of small science- } \\
\text { intensive enterprises through federal and regional scientific } \\
\text { divisions of authorities. } \\
\text { Opening of free telephone line with representatives of } \\
\text { databases, for receipt of necessary information on transfer } \\
\text { of technologies; edition of catalogs, of the centers of } \\
\text { technology transfer training in mechanisms of effective } \\
\text { realization of technologies transfer. }\end{array}$ & $\begin{array}{l}\text { The financial help to technology transfer centers for the purpose of } \\
\text { innovations effective promotion by the small science-intensive } \\
\text { enterprises. Similar measures are expedient also to apply in Russian } \\
\text { centers of technology transfer. }\end{array}$ \\
\hline Great Britain & $\begin{array}{l}\text { Increasing the on-budget expenditures for the purpose of } \\
\text { scientific and technical infrastructure development. } \\
\text { The appraisal has been carried out by the British } \\
\text { technological group, directed on determination of economic } \\
\text { value of innovative ideas and the subsequent financing of } \\
\text { the most perspective, patenting British inventions abroad } \\
\text { and protection of foreign intellectual property in Great } \\
\text { Britain. }\end{array}$ & $\begin{array}{l}\text { The information base of innovative projects in the centers of } \\
\text { innovative development, financing the implementation of cost- } \\
\text { effective innovative ideas. } \\
\text { State support for basic and applied research. }\end{array}$ \\
\hline Germany & $\begin{array}{l}\text { Provision by federal government of subsidies (can reach } 46 \\
\% \text { from the total cost of the ordered research and } \\
\text { development) for obtaining by small science-intensive } \\
\text { enterprises of assistance at realization of technologies } \\
\text { transfer. }\end{array}$ & $\begin{array}{l}\text { For Russian centers of technology transfer it is rational to have a } \\
\text { financial support not just strictly, for technology transfer, but also for } \\
\text { search and organization of communications between the inventor, } \\
\text { center of technologies transfer and customer. }\end{array}$ \\
\hline France & $\begin{array}{l}\text { The government retains an extensive network of } \\
\text { specialized regional centers of innovations and transfer of } \\
\text { technologies. }\end{array}$ & $\begin{array}{l}\text { The given direction well-handled also by Russian centers of } \\
\text { technology transfer for support and regulation of relationship among } \\
\text { themselves as often each of them deals within the innovations of } \\
\text { certain profile. The corresponding and timely exchange of information } \\
\text { on commercial basis will stimulate an effective technology transfer. }\end{array}$ \\
\hline Poland & $\begin{array}{l}\text { Financing by the government of creation of non-commercial } \\
\text { centers of technology transfer and those projects in which } \\
\text { the EU countries are interested. }\end{array}$ & $\begin{array}{l}\text { Russia is on similar way of innovative development; however there is } \\
\text { a multitude unresolved questions in the sphere of state protectionism } \\
\text { and financing of technology transfer centers. }\end{array}$ \\
\hline $\begin{array}{l}\text { Finland, Belgium, } \\
\text { Denmark, Portugal }\end{array}$ & $\begin{array}{l}\text { Creation on regional basis of special centers which activity } \\
\text { is directed on organization of cooperation of universities } \\
\text { and industry, interdisciplinary centers, innovative centers } \\
\text { of technology transfer in small and medium business. }\end{array}$ & $\begin{array}{l}\text { Creation and development of federal and research universities, } \\
\text { acting as a platform integrating science, business and education in } \\
\text { the regions. }\end{array}$ \\
\hline $\begin{array}{l}\text { China, South } \\
\text { Korea, Thailand, } \\
\text { Singapore, } \\
\text { Taiwan, Russia }\end{array}$ & $\begin{array}{l}\text { The main lever of successful technology transfer is the } \\
\text { preferential taxation, which directions has a flexible nature } \\
\text { and depends on strategic reference points of the state in } \\
\text { the field of science and industry. }\end{array}$ & $\begin{array}{l}\text { Creation and support of innovative special economic zones such as } \\
\text { the use of preferential tax regimes. }\end{array}$ \\
\hline
\end{tabular}

The western countries in due time have faced a problem of unpreparedness of scientists for participation in active promotion of the developments in production. Many researchers with suspicion have regarded the ideas of commercialization of research process results, intellectual property protection, etc. It took long-lasting period in leading western countries to form the basic elements of technologies process transfer organization (Zaramenskikh, 2013). 
The analysis of American experience in organization of technologies transfer shows that the reason of high effectiveness of research process and a successful interaction of science and industry in the USA, expressed in the achievements of this country in the field of high technologies, is hidden on availability of the debugged mechanism, allowing to avoid the red tape, corruption and other abuses, braking the development of technologies transfer in Russia. This mechanism has arisen in the USA due to serious efforts of the state on legislative regulation of innovative activity and stimulation of such activity at universities and other non-commercial research organizations.

Creation in Germany of specialized organizations on technologies transfer led to growth of number of concluded license agreements, created the effective instrument of transition from planned economy to market economy in eastern lands. Thereat the role of universities participating in technologies transfer, first of all, consists in preparation of skilled researchers that is a distinctive feature of development of German innovative mode. Nevertheless, the German experience also bears in itself an idea of labor division in the course of technologies transfer.

Great Britain's experience is interesting by special approach on organization of technologies transfer which can find an application in Russia as well. Less, than for twenty years, a movement on creation of scientific parks in Great Britain have been promoting an effective technologies transfer owned by universities - founders of scientific parks, forthcoming new high-technology entities, new workplaces creation and attraction of investments in high-technology industries.

Though the organization of technologies transfer has the features for each specific country which is connected to distinction in reference conditions, cultural traditions etc., nevertheless, there are certain crucial elements, general for the majority of developed countries in the world, providing the effectiveness of system interaction between the science and industry, namely: the equilibration of rights and duties, the guarantees of observance of intellectual property rights, the prevalent culture of entrepreneurship and the academic ethics. Thus many elements of this system are in addition being supervised and undertaken by the state, as, for example, the protection of intellectual property rights. In lack of these conditions as this research have shown, one of the main difficulties consists in formation of technologies transfer in Russia.

The common feature for the considered forms of technologies transfer organization is that a special place in the system of mutual relations of science and the industry is occupied by specially created structures which are carrying out a preparatory work on technologies transfer and tracking an accomplishment of signed agreements with the industry.

Taking into consideration the distinctions of subjects of the Russian Federation on scientific potential and concentration of industrial productions, it is reasonable to make use of experience of the USA on organization of the "direct" transfer in major scientific and industrial centers. The "indirect" transfer, i.e. with participation of professional intermediaries (experience of Germany), can be used in regions with lower scientific potential and poor concentration of productions. In the regions industrially developed, where it is possible to have the shared financing of scientific and technological infrastructure from the state, regional power and major enterprises, there can be used the experience of Great Britain on creation of scientific parks (Shaposhnikov, 2004).

Acceleration of tempo of technologies transfer is necessary to realize at four levels of innovative system (fig. 1): international, national, industry and intra-organizational. The provided actions will allow overcoming problems of technologies transfer in Russia, such as, for example, duplication of functions of infrastructure subjects, uneven placement on the territories of Russia and lack of information exchange.

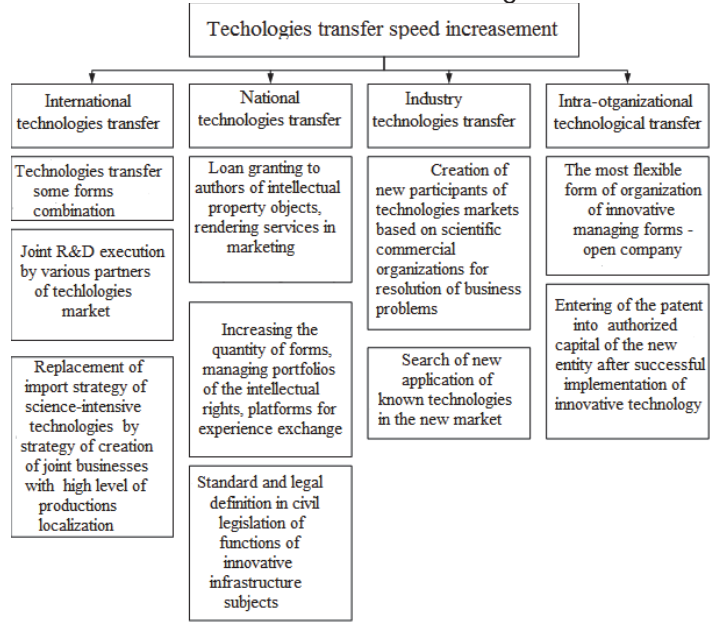

Figure 1. Innovative system levels 
One of the key problems of technologies transfer development in industries is the replacement of intellectual property transfer in the branches onto other forms of the transfer (the agreement on accomplishment by R\&D without obligation to register the intellectual property, non-commercial distribution of information in the form of report on research engineering and publications) (Bukharova, 2013).

\section{Concluding Remarks}

The results of research show that the organization and functioning of the centers of technology transfer in the world depends on technological and economic level of state development (Scott, 1997). In particular, for India and China the policy of the accelerated development of innovative technologies accounts for by application of target programs of public financing (direct methods). For Russia the use of indirect methods which is connected to increase in number of the Russian and foreign investors is typical.

The creation of a balanced system of technology transfer in Russia will improve profitability in the field of innovative entrepreneurship in Russia, will open up opportunities for Russian developers of foreign investment resources. The Russian Federation must implement two ways of improving the process of technology transfer and accelerate innovation. The first direction is the establishment of new structures to integrate and co-operating innovative active subjects for technology transfer. The second - the formation of tools and mechanisms that support and regulate this cooperation, such as contractual basis licensing of intellectual property, etc.

The results of research presented in this paper were obtained with the financial support of the Ministry of Education of the Russian Federation within the framework of the project "Creation of a plant for manufacture of multifunctional mobile hardware-software complex of prolonged cardiac monitoring and ergometry" by government decree № 218 of 09.04.2010, the research was carried out in the FSAEI HPE SFU (SFedU).

\section{References}

Bukharova, M.M. (2013). Management of technological innovations transfer: the industry chain of values. Theory problems and management practices, 111-119.

Bykovsky, V.V.; Minko, L. V.; Korobova, O.V.; Bykovskaya, E. V. and Zolotaryova, G. M. (2006). Organization and financing of innovations (p. 116). Tambov publishing house: Publisher TGTU.

Ilyin, P.V. (2013). Foreign experience of technology transfer - in Russian practice. Economic and social changes: facts, trends, forecast, $1(25)$.

Research INSEAD: The Global Innovation Index 2014 (2014). The Centre for Humanitarian Technologies, from http://www.wipo.int/ edocs/pubdocs/en/economics/gii/gii_2014.pdf

Shaposhnikov, A.A. (2004). Technologies transfer in the scientific and educational sphere (Avto-library-research, Tomsk).

Arora, A. and Gambardella, A. (2010). The market for technology Handbook of Economics of Innovation. Elsevier: North Holland, Amsterdam (forthcoming).

Bonkovsky and Klepka, M. (2005). Instruments of innovation support in small and medium-sized enterprises. Experiences have got Poland and EU. Polish association of the centers of innovations and business (pp. 186). Drogobich-Poznan.

Ceccagnoli, M. and Hicks, D. (2009). Merges, joint ventures and licensing as commercialization strategies for technology based firms.

Reamer, A. (2003). Technology Transfer and Commercialization: Their Real in Economic Development. Economic Development Administration U.S. Department of Commerce Report.

Scott, D. (1997). Expanding the Content Base of Technology Education: Technology Transfer as a Topic of Study, Journal of technology education, 8 (2).

Sharif, M. and Kabir, R (1976). System dynamics modeling for forecasting multilevel technological substitution. Technol. Substitution Forecast (pp: 21-47). Techn. and Appl. N.Y.

Zaramenskikh, E.P. (2013). Directions of Stimulation of Technology Transfer Abroad and Possibilities of Use in Russia. World Applied Sciences Journal (Education, Law, Economics, Language and Communication), 27, 385-388.

Switzerland's official information portal from http://www.swissworld.org/ru/nauka/nauka___gosudarstvo/transfer_tekhnologii/ 
ISSN 2039-2117 (online) ISSN 2039-9340 (print)
Mediterranean Journal of Social Sciences MCSER Publishing, Rome-Italy
Vol 6 No 3 S4 May 2015 